\title{
MORFOLOGIA POLÍNICA DE POPULAÇÕES AMAZÔNICAS DE Elaeis oleifera ${ }^{1}$
}

\author{
Lúcia Helena Pinheiro MARTINS ${ }^{2}$, Ires Paula de Andrade MIRANDA ${ }^{3}$, \\ Cley Donizeti NUNES ${ }^{4}$
}

\begin{abstract}
RESUMO - Elaeis oleifera (Kunth) Cortés - Arecaceae (caiaué) apresenta características vantajosas para a hibridação com o dendê E. guineensis que variam entre populações. Com o objetivo de contribuir para a discriminação de populações amazônicas, caracterizou-se a morfologia do pólen de dez populações de caiaué (Acajatuba, Amatari, Autazes, BR-174, Careiro, Manicoré, Maués, Moura, Novo Aripuanã e Tefé). Utilizou-se o método da acetólise para eliminação do conteúdo celular e observou-se o tamanho, forma, abertura e superfície dos grãos de pólen. A população Novo Aripuanã apresentou maior tamanho médio dos grãos de pólen $(49,0 \mu \mathrm{m})$ e as populações Amatari, BR-174 e Moura os menores (42,5 a 44,0 $\mu \mathrm{m})$. Os grãos de pólen são elípticos ou piriformes, com abertura monocolpada e superfície microrreticulada. Observou-se, também, anormalidades morfológicas em alguns grãos. A morfologia polínica separou as populações amazônicas em três grupos e, quando associada a outras análises (isoenzimas e DNA), pode representar uma ferramenta importante na discriminação de populações.
\end{abstract}

Palavras-chave: palinologia, palmeiras, caiaué, descritores, discriminação de populações.

\section{Pollen morphology of Amazonian populations of Elaeis oleifera}

\begin{abstract}
Elaeis oleifera (Kunth) Cortés (American oil palm) has advantageous characteristics for hibridization with E. guineensis which vary among populations. In order to contribute to population discrimination, we studied pollen morphology of ten Amazonian populations (Acajatuba, Amatari, Autazes, BR-174, Careiro, Manicoré, Maués, Moura, Novo Aripuanã, Tefé). The acetolysis method was used to eliminate cell contents and enable observations on pollen size, shape, aperture and exine surface. Pollen grains from the Novo Aripuanã population had the largest mean grain size $(49 \mu \mathrm{m})$ and populations from Amatari, BR-174 and Moura the smallest ( 42.5 to $44 \mu \mathrm{m})$. Pollen is elliptic or piriform, aperture type is monocolpate and exine surface is microreticulate. Pollen grains with morphological abnormalities were also found. Pollen morphology discriminated three groups of Amazonian populations and offers an important tool for population discrimination, especially when associated with other analyses.
\end{abstract}

Key-words: palynology, palms, American oil palm, descriptors, population discrimination.

\section{INTRODUÇÃO}

Elaeis oleifera (Kunth) Cortés, conhecida como caiaué, vem sendo empregada para cruzamentos com E. guineensis Jacq. (dendê). Apesar da baixa produtividade em óleo (Meunier \& Boutin, 1975; Ooi et al., 1981), apresenta características vantajosas para exploração comercial, como estipe de porte pequeno, melhor qualidade do óleo e maior

\footnotetext{
${ }^{1}$ Parte da Dissertação de Mestrado (INPA/UA) da primeira autora, com apoio financeiro de PPD 0838/95. ${ }^{2}$ Instituto Nacional de Pesquisas da Amazônia - INPA, Coordenação de Pesquisas em Botânica, Caixa Postal 478, CEP 69083-000, Manaus, AM / Bolsista de Mestrado CNPq.

${ }^{3}$ Instituto Nacional de Pesquisas da Amazônia - INPA, Coordenação de Pesquisas em Botânica, Caixa Postal 478, CEP 69083-000, Manaus, AM.

${ }^{4}$ Empresa Brasileira de Pesquisa Agropecuária - Clima Temperado, Caixa Postal 403, CEP 96001-970, Pelotas, RS.
} 
tolerância a pragas e doenças. A facilidade de hibridação aumenta a variabilidade disponível para seleção, importante condição para o melhoramento genético. Nos híbridos, $E$. oleifera mostra maior dominância sobre $E$. guineensis, sugerindo que o caiaué é ancestral e o dendê derivado (Corley, 1976). Certas populações de E. oleifera apresentam características superiores quando cruzadas com dendê comercial, sugerindo a importância de discriminar suas populações.

Pesquisas com o caiaué agruparam as populações amazônicas segundo caracteres vegetativos e reprodutivos (Barcelos, 1986), isoenzimas (Ghesquière et al., 1987) e DNA (Barcelos et al., 1999). A morfologia polínica também permite agrupar populações, o que, segundo Salgado-Labouriau (1973), constituise em uma forma de abordar problemas genéticos, além de ser reconhecida como técnica taxonômica para o estudo de famílias botânicas. Em trabalhos realizados com dendê enfatizando vários aspectos, Hartley (1988) citou Tan \& Rao (1979) com relação ao estudo da morfologia polínica desta espécie, porém, sem mencionar a variabilidade nem a morfologia polínica de caiaué. Desta forma, o presente estudo teve como objetivo a caracterização morfológica do pólen de E. oleifera para discriminação de populações amazônicas, bem como, subsidiar pesquisas relacionadas ao melhoramento vegetal dessa palmeira.

\section{MATERIAL E MÉTODOS}

Foram utilizados grãos de pólen de 4 indivíduos, com idades entre 9 e 11 anos, provenientes, cada um, de 10 populações naturais do caiaué da Amazônia brasileira (Figura 1), mantidas no Banco de Germoplasma da Estação Experimental do Rio Urubu EMBRAPA/CPAA (Empresa Brasileira de Pesquisa Agropecuária/Centro de Pesquisas Agroflorestais da Amazônia Ocidental), localizada a $140 \mathrm{~km}$ de Manaus $(\mathrm{km} 82 \mathrm{da}$ rodovia AM-10), no Distrito Agropecuário da SUFRAMA (Superintendência da Zona Franca de Manaus), às margens do rio Urubu, Rio Preto da Eva, AM. A coleta das inflorescências foi feita na fase de antese das flores masculinas, como recomendado pelo "Institut de Recherches pour les Huiles et les Oléagineux" - IRHO (1983).

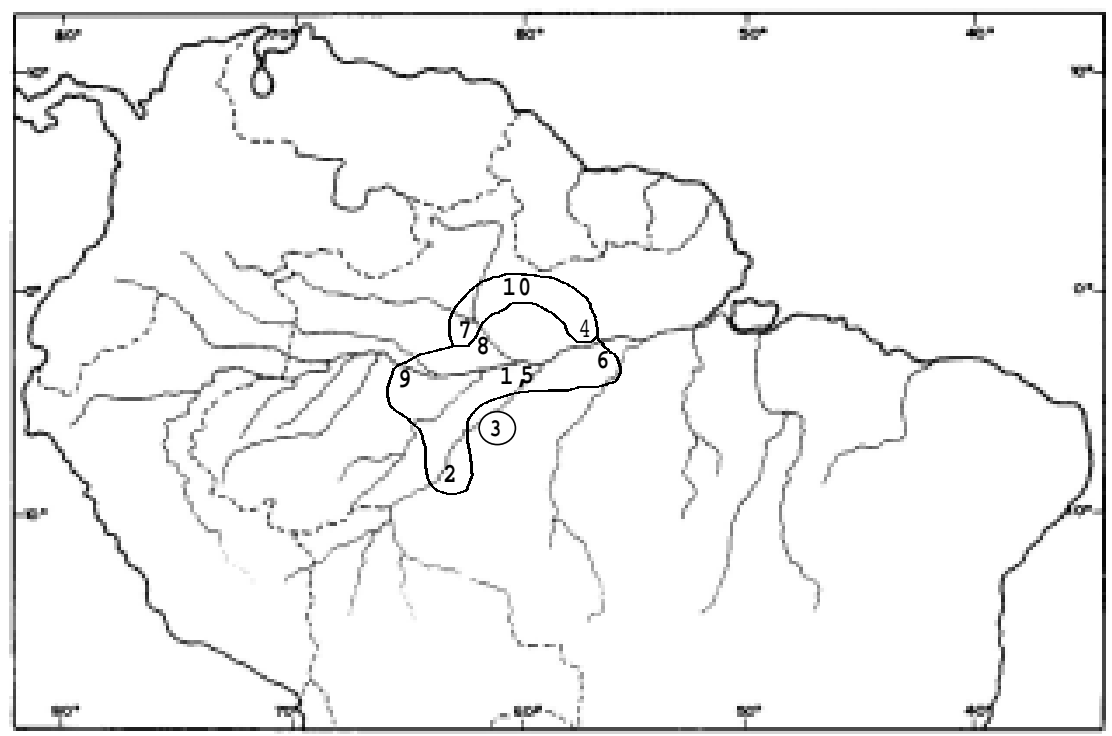

Figura 1 - Distribuição geográfica das populações estudadas de caiaué (Elaeis oleifera (Kunth) Cortés) e agrupamento segundo tamanho do pólen. 1. Careiro; 2. Manicoré; 3. Novo Aripuanã; 4. Amatari; 5. Autazes; 6. Maués; 7. Moura; 8. Acajatuba; 9. Tefé; 10. BR-174. 
Para caracterização dos grãos de pólen, utilizou-se o método da acetólise de Erdtman (1960), onde os grãos de pólen foram submetidos à acetólise (hidrólise ácida), que consiste em anidrido acético e ácido sulfúrico na proporção de 9:1, eliminando seu conteúdo celular para observação da parede externa do pólen (exina). Os grãos de pólen foram montados em lâminas com gelatina glicerinada lutadas em parafina. As descrições polínicas e nomenclatura utilizadas foram baseadas nos trabalhos de Erdtman (1966), Thanikaimoni (1970) e Barth \& Melhem (1988) e as medidas do diâmetro máximo ou eixo maior de 25 grãos foram obtidas com uma ocular micrométrica linear Zeiss 10x, adaptada ao microscópio óptico Leitz Laborlux com objetiva de 40x (Faegri \& Iversen, 1975). As fotomicrografias em microscopia eletrônica de varredura (MEV) foram obtidas no microscópio eletrônico Jeol T20 no Jardim Botânico de Kew, após preparação conforme Miranda (1993). O delineamento experimental foi completamente casualizado e a comparação das médias foi feita com o teste de Duncan, a 5\% de probabilidade (Montgomery, 1991).

\section{RESULTADOS E DISCUSSÃO}

\section{Morfologia polínica}

Os grãos de pólen do E. oleifera são heteropolares e o tamanho médio do diâmetro maior ou eixo maior variou de 42,5 a 49,0 $\mu \mathrm{m}$ (Tabela 1) estando próximo ao encontrado por Punt \& Wessels Boer (1966), em torno de 40 $\mu \mathrm{m}$, e por Thanikaimoni (1970), entre 38 a 55 $\mu \mathrm{m}$. Entretanto, é inferior ao intervalo observado por Roubik \& Moreno (1991) para E. oleifera do Suriname (50 a $63 \mu \mathrm{m})$. A maior média foi da população de Novo Aripuanã $(49,0)$, sendo significativamente diferente das demais, e as menores médias foram observadas nas populações de BR-174, Moura e Amatari (42,5 a 44,0), não sendo encontradas diferenças significativas entre essas médias. A morfologia polínica separou em três grupos relacionados ao tamanho médio do diâmetro maior ou eixo maior. $\mathrm{O}$ grupo com maior eixo encontrado foi a população Novo Aripuanã, o segundo grupo as populações Careiro, Manicoré, Autazes, Maués, Acajatuba e Tefé, e um terceiro grupo, Amatari, Moura e BR-174 (Tabela 2).

Tabela 1 - Comparação do tamanho dos grãos de pólen de dez populações naturais de Elaeis oleifera (Kunth) Cortés estudadas, com as medidas em $\mu \mathrm{m}$ dos respectivos grãos.

\begin{tabular}{lcccccccc}
\hline Populações & \multicolumn{2}{c}{ Média } & \multicolumn{2}{c}{ Desvio Padrão } & \multicolumn{2}{c}{$\begin{array}{c}\text { Intervalo de Confiança } \\
(1-\alpha)=0,95\end{array}$} & \multicolumn{2}{c}{ Exina } \\
& DM & Dm & DM & Dm & DM & Dm & Sexina & Nexina \\
\hline N. Aripuanã & 49,0 & 36,3 & 0,44 & 0,63 & $(47,5 ; 50,4)$ & $(34,3 ; 38,3)$ & 0,98 & 0,98 \\
Manicoré & 46,5 & 31,0 & 1,02 & 1,21 & $(43,2 ; 49,8)$ & $(27,1 ; 34,8)$ & 0,71 & 0,65 \\
Maués & 46,3 & 33,8 & 0,46 & 1,47 & $(44,8 ; 47,8)$ & $(29,1 ; 38,5)$ & 0,90 & 0,87 \\
Careiro & 46,6 & 32,7 & 0,41 & 0,83 & $(45,3 ; 47,9)$ & $(30,1 ; 35,4)$ & 0,71 & 0,65 \\
Amatari & 44,0 & 32,4 & 0,75 & 1,00 & $(41,6 ; 46,4)$ & $(29,2 ; 35,7)$ & 0,71 & 0,65 \\
Autazes & 46,3 & 33,5 & 1,28 & 1,21 & $(42,3 ; 50,4)$ & $(29,6 ; 37,4)$ & 0,82 & 0,81 \\
Tefé & 45,6 & 33,5 & 0,58 & 0,74 & $(43,8 ; 47,4)$ & $(31,1 ; 35,9)$ & 0,96 & 0,92 \\
Acajatuba & 45,7 & 31,9 & 1,01 & 0,85 & $(42,5 ; 48,9)$ & $(29,2 ; 34,7)$ & 0,75 & 0,68 \\
Moura & 42,9 & 31,1 & 0,23 & 0,29 & $(41,9 ; 43,9)$ & $(29,8 ; 32,3)$ & 0,72 & 0,61 \\
BR-174 & 42,5 & 25,9 & 0,35 & 0,71 & $(40,9 ; 43,9)$ & $(22,8 ; 28,9)$ & 0,62 & 0,55 \\
\hline
\end{tabular}

DM: Diâmetro Maior

Dm: Diâmetro menor 
Tabela 2 - Valores médios ( \pm desvio padrão) do diâmetro maior dos grãos de pólen de Elaeis oleifera (Kunth) Cortés de 10 populações amazônicas mantidas na Estação Experimental de Dendê do Rio Urubu EMBRAPA, Amazonas em 1996.

\begin{tabular}{lll}
\hline Populações & \multicolumn{2}{l}{ Diâmetro Maior $(\mu \mathrm{m})$} \\
\hline Novo Aripuanã & $49,0 \pm 0,44$ & a * \\
Careiro & $46,6 \pm 0,41$ & b \\
Manicoré & $46,5 \pm 1,02$ & b c \\
Autazes & $46,3 \pm 1,28$ & b c \\
Maués & $46,3 \pm 0,46$ & b c \\
Acajatuba & $45,7 \pm 1,01$ & b c \\
Tefé & $45,6 \pm 0,58$ & b c \\
Amatari & $44,0 \pm 0,75$ & c d \\
Moura & $42,9 \pm 0,23$ & d \\
BR-174 & $42,5 \pm 0,35$ & d \\
Média das populações & $45,5 \pm 1,94$ & \\
\hline
\end{tabular}

* Médias seguidas por letras distintas diferem entre si pelo teste de Duncan ao nível de $5 \%$ de significância

Quanto à forma e abertura, os grãos de pólen são elipsóides ou irregularmente elípticos, com abertura monocolpada ou piriformes e, poucas vezes, triangulares, com abertura tricotomocolpada (Figura 2). De acordo com Thanikaimoni (1970), o dimorfismo é freqüente nas palmeiras. Harley (1990) acrescenta que esses grãos de pólen ocorrem em combinação de formas, isto é, espécies com grão de pólen apresentando mais de uma forma, e que a condição tricotomo indica um grau de especialização. De modo geral, essa variabilidade polínica pode ocorrer na família e, provavelmente, a forma dos grãos desta espécie esteja relacionada com o tipo de abertura: grãos de pólen triangulares apresentam abertura tricotomocolpada; as outras formas elipsóides irregulares são monocolpadas. Harley (1999) classificou em tipos de aberturas pouco freqüentes, espécies com grãos tricotomosulcados simétricos sem a ocorrência de monosulcados simétricos, incluindo $E$. guineensis. Em E. oleifera, além dos tipos anteriormente relatados, observou-se também, grãos triangulares na maioria das populações, exceto em Moura e BR-174, o que pode representar uma característica de discriminação de grupos de populações, mas que requer amostragem maior para determinar sua utilidade.
A análise de superfície mostrou que a exina dos grãos das populações é microrreticulada, considerando-se a definição de Praglowski \& Punt (1973) que estabelece o diâmetro do lúmen menor que $1 \mu \mathrm{m}$ (Figura $2 \mathrm{~b}, \mathrm{~d}$ ).

\section{Anormalidade morfológica}

Foram constatadas formas de grãos de pólen de E. oleifera com aberturas colapsadas, obstruídas pela esporopolenina ou apresentando corpúsculos de pequeno talho na exina em todas as populações estudadas (Figura 3). Estas formas irregulares podem ser consideradas másformações de origem meiótica (Thanikaimoni, 1970), considerando a obstrução das aberturas pela esporopolenina. $\mathrm{O}$ autor acrescenta que esse fenômeno pode ocorrer quando as plantas não estão em seu ambiente natural, embora este trabalho tenha verificado as anormalidades polínicas nos ecótipos naturais de Barcelos (1986).

A anormalidade polínica também foi encontrada por Miranda (1986, 1993) em pupunheira (Bactris gasipaes Kunth), palmeira cultivada, onde também foram observados grãos de pólen com corpúsculos na exina, sugerindo que esses grãos de pólen anormais poderiam ser oriundos de um estado híbrido da espécie. Possivelmente, a má-formação encontrada em alguns grãos de E. oleifera tenha essa origem.

\section{Relações entre as populações}

As populações amazônicas foram separadas em três grupos pela morfologia polínica, enquanto que Barcelos (1986) identificou dois ecótipos principais. O primeiro, formado pelos indivíduos coletados ao longo da rodovia BR-174, foi considerado uma população natural. $O$ outro foi caracterizado por populações ocorrendo em solo antropogênico (terra preta do índio), incluindo Novo Aripuanã, Manicoré e Maués. $\mathrm{O}$ autor classificou ainda como um grupo intermediário as populações Careiro, Amatari, Autazes, Tefé, Acajatuba e Moura, pois não constituíram um ecótipo definido, apesar de apresentarem características mais próximas das introduzidas pelos indígenas. 

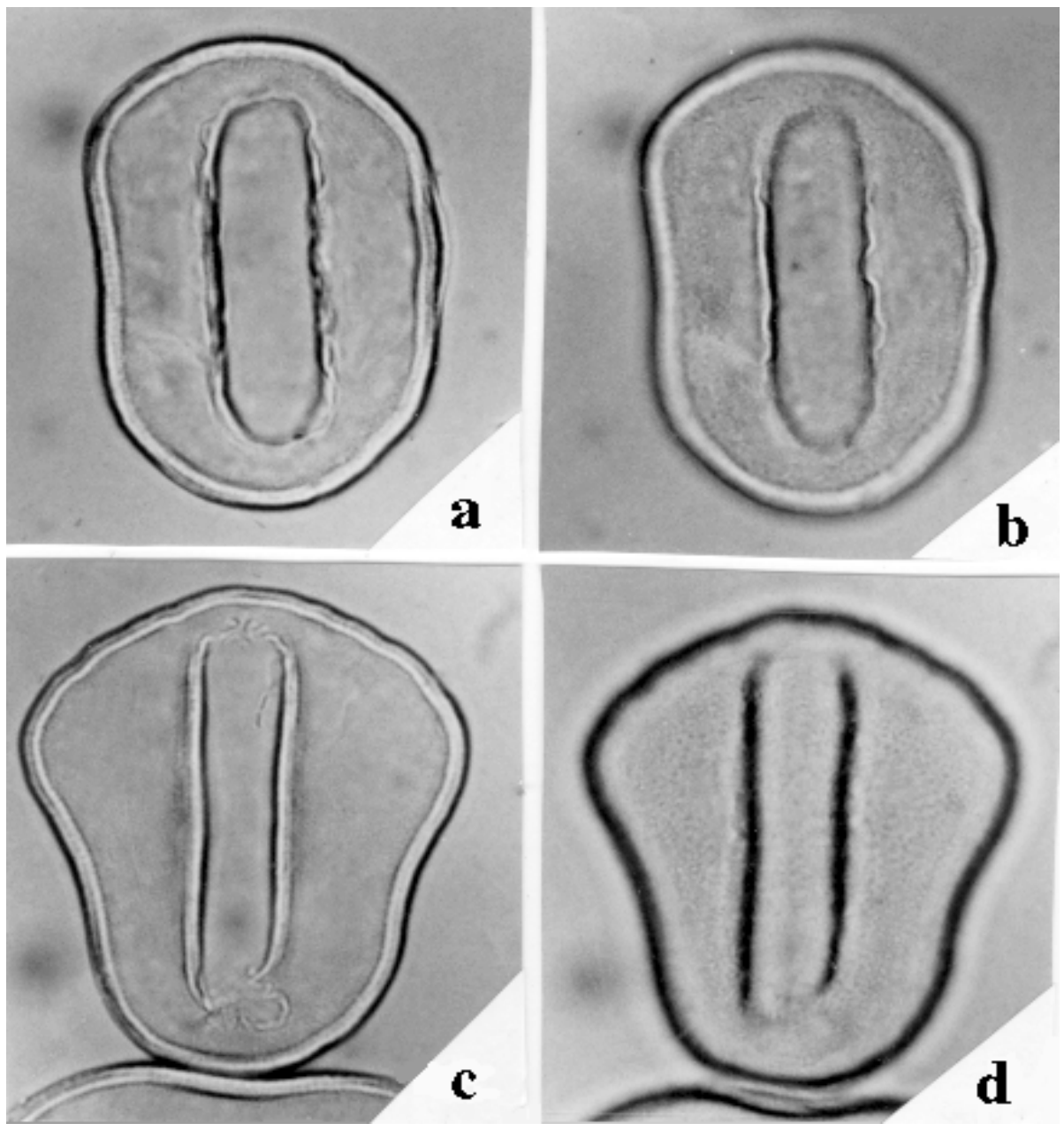

Figura 2 - Dimorfismo polínico de grãos de pólen de Elaeis oleifera. a) grão de pólen elíptico (população Tefé), evidenciando a abertura; b) grão de pólen elíptico (população Tefé), evidenciando a ornamentação, superfície microrreticulada; c) grão de pólen piriforme (população Careiro), evidenciando a abertura; d) grão pólen piriforme (população Careiro), evidenciando a ornamentação, superfície microrreticulada (MO x1000).

A análise do polimorfismo enzimático do caiaué discriminou as populações em sete grupos, relacionando a rede fluvial do Amazonas com a organização da variabilidade enzimática (Ghesquière et al., 1987). As provas de DNA nuclear pela análise de marcadores RFLP (Restriction Fragment Length Polymorphism) revelaram cinco grupos grandes, Manaus, BR-174, Rio Negro, Rio Solimões e Rio Madeira (Barcelos et al., 1999) (Tabela 3).
Os autores acrescentaram resultados da análise do genoma mitocondrial que também dividiu em cinco mitótipos os acessos brasileiros de $E$. oleifera. Um grupo reuniu as populações Manaus, Rio Solimões, Rio Negro e BR-174; um segundo grupo separou a população do Alto Solimões; e três grupos estavam relacionados a populações do Rio Madeira.

Apesar da diferença dos materiais, haplóide e diplóide, é possível confirmar alguns 

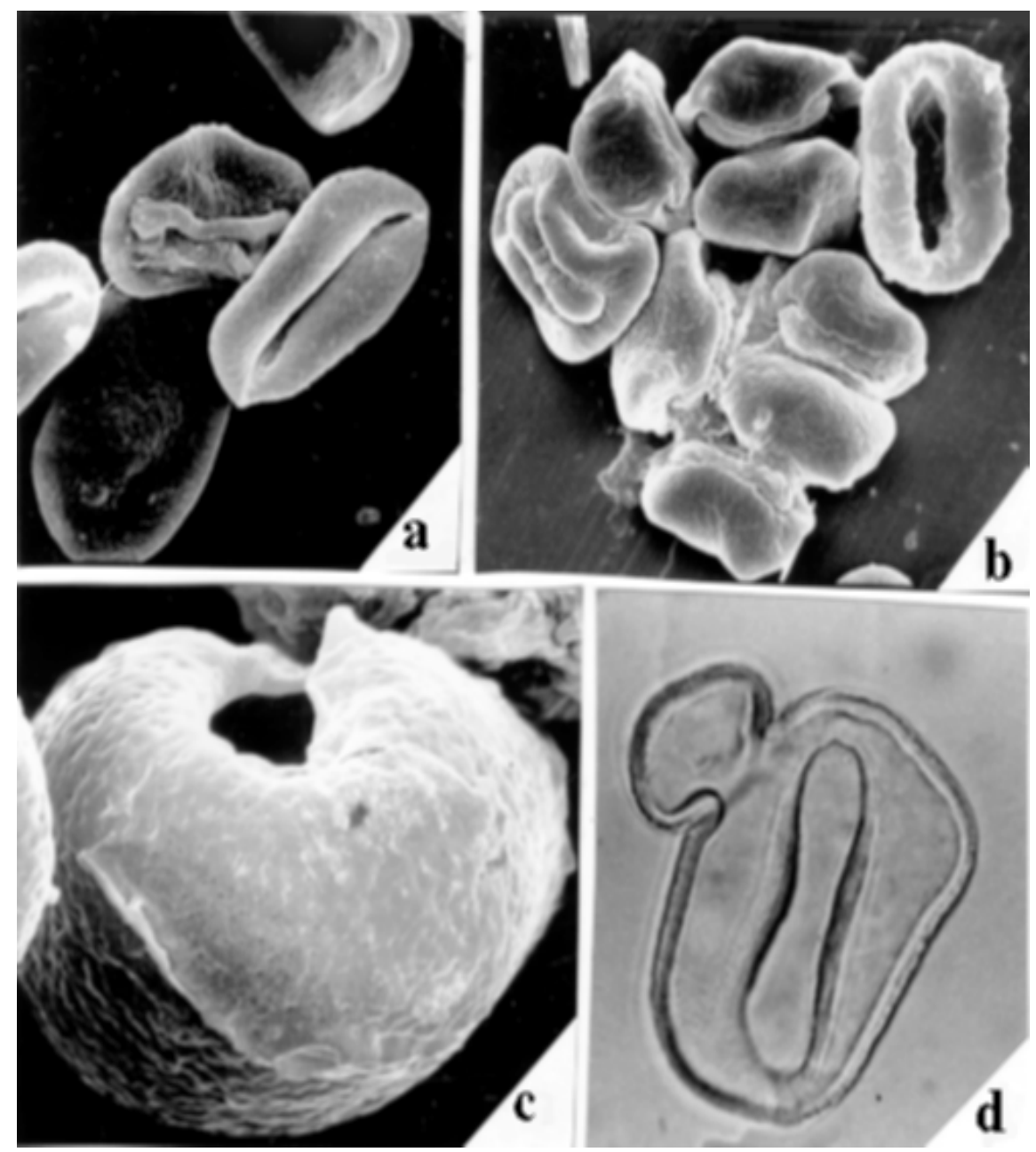

Figura 3 - Má-formação polínica de grãos de pólen de Elaeis oleifera. a), b) obstrução da abertura do pólen pela esporopolenina (populações Maués e Amatari, respectivamente) MEV x1000; c) abertura colapsada (população Tefé), MEV x4000; d) abaulamento da parede do grão (população Tefé), MO x1000.

agrupamentos. A caracterização dos ecótipos do caiaué (Barcelos, 1986), isoenzimas (Ghesquière et al., 1987) e DNA nuclear (Barcelos et al., 1999) identificaram como um grupo a população BR174 embora a análise polínica tenha incluído neste grupo, populações dos Rios Amazonas e Negro.

Os grupos coincidem ou não dependendo do estudo realizado. A análise de isoenzimas discriminou mais as populações, diferente da análise polínica que as dividiu em três grupos estatisticamente separados e coincidindo com a localização geográfica: populações do norte do Amazonas, do Baixo Rio Madeira e um grupo de populações espalhadas pelos rios Solimões, Amazonas e afluentes menores, desde Tefé até Maués. Outra observação é que a análise de isoenzimas e morfologia polínica identificaram a população Novo Aripuanã, no Baixo Rio Madeira, como um grupo isolado, diferente da caracterização dos ecótipos e pelo DNA nuclear que incluíram Manicoré como população do Madeira. Possivelmente, esse isolamento possa ser 
explicado pelo efeito dos fundadores, ou seja, o material genético de uma população apresenta uma parte da variação total da população fonte.

A morfologia polínica tem-se mostrado como uma ferramenta importante na discriminação de populações e, associada a outras análises, pode completar informações sobre espécies cultivadas. Em relação ao caiaué, esse quadro torna novos ensaios promissores na área da biopalinologia, citologia, fisiologia e bioquímica polínica.

Tabela 3 - Comparação dos agrupamentos de dez populações amazônicas de Elaeis oleifera (Kunth) Cortés aqui estudados, conforme o tipo de análise.

\begin{tabular}{|c|c|c|c|c|c|c|c|}
\hline Morfologia $^{1}$ & G & Isoenzimas ${ }^{2}$ & G & Pólen & G & DNA $^{3}$ & G \\
\hline BR -174 & 1 & BR - 174 & 1 & BR - 174 & 1 & BR -174 & 1 \\
\hline Novo Aripuanã & 2 & Novo Aripuanã & 2 & Amatari & 1 & Novo Aripuanã & 2 \\
\hline Manicoré & 2 & Manicoré & 3 & Moura & 1 & Manicoré & 2 \\
\hline Maués & 2 & Careiro & 4 & Novo Aripuanã & 2 & Careiro & 3 \\
\hline Careiro & 3 & Autazes & 4 & Manicoré & 3 & Amatari & 3 \\
\hline Amatari & 3 & Amatari & 4 & Autazes & 3 & Autazes & 3 \\
\hline Autazes & 3 & Maués & 4 & Careiro & 3 & Maués & 3 \\
\hline Tefé & 3 & Tefé & 5 & Maués & 3 & Tefé & 4 \\
\hline Acajatuba & 3 & Acajatuba & 6 & Tefé & 3 & Acajatuba & 5 \\
\hline Moura & 3 & Moura & 6 & Acajatuba & 3 & Moura & 5 \\
\hline
\end{tabular}

* Grupo

${ }^{1}$ Barcelos (1986) ${ }^{2}$ Ghesquière et al. (1987) ${ }^{3}$ Barcelos et al. (1999)

\section{AGRADECIMENTOS}

Os autores agradecem ao Dr. Ghillean T. Prance e ao Jardim Botânico de Kew - Reino Unido pela microscopia eletrônica de varredura; ao Dr. Charles R. Clement CPCA/INPA pelas valiosas sugestões; ao Conselho Nacional de Pesquisas (CNPq) pela concessão de bolsa de mestrado para a primeira autora; à Empresa Brasileira de Pesquisa Agropecuária - Centro Pesquisas Agroflorestais da Amazônia Ocidental EMBRAPA/CPAA e Instituto Nacional de Pesquisa da Amazônia - INPA pelo apoio logístico e financeiro.

\section{BIBLIOGRAFIA CITADA}

Barcelos, E. 1986. Características genéticoecológicas de populações naturais de caiaué (Elaeis oleifera (H.B.K.) Cortés) na Amazônia brasileira. Dissertação de Mestrado, PPG INPA/FUA, Manaus. $108 \mathrm{p}$.

Barcelos, E.; Second, G.; Kahn, F.; Amblard, P.; Lebrun, P.; Seguin, M. 1999. Molecular markers applied to the analysis of genetic diversity and to the biogeography of
Elaeis (Palmae). In: Henderson, A.; Borchsenius, F. (Eds.). Evolution, variation and classification of palms. Memoires of the New York Botanical Garden, 83:191201.

Barth, O.M.; Melhem, T.S. 1988. Glossário ilustrado de palinologia. Ed. Unicamp, Campinas. $75 \mathrm{p}$.

Corley, R.H.V. 1976. The genus Elaeis. In: Corley, R.H.V.; Hardon, J.J.; Wood, B.J. (Eds.). Oil Palm Research. Developments in Crop Science 1. Elsevier, Amsterdam. pp.3-5.

Erdtman, G. 1960. The acetolysis method. A revised description. Svensk Botanisk Tidskrift, 54(4):561-564.

Erdtman, G. 1966. Pollen morphology and plant taxonomy. Angiosperms. 2 ed. Hafner, New York. 553p.

Faegri, K.; Iversen, J. 1975. Textbook of pollen analysis. $3^{\text {rd }}$ Ed. Blackwell Scientific, Oxford. 295p.

Ghesquière, M.; Barcelos, E.; Santos, M. de M.; Amblard, P. 1987. Polymorphisme enzymatique chez Elaeis oleifera H.B.K. (E. melanococca). Oléagineux, 42(4):143150. 
Harley, M.M. 1990. Occurrence of simple, tectate, monosulcate or trichotomosulcate pollen grains within the Palmae. Review of Palaeobotany and Palynology, 64:137-147.

Harley, M.M. 1999. Palm pollen:overview and examples of taxonomic value at species level. In: Henderson, A.; Borchsenius, F. (Eds.). Evolution, variation and classification of palms. Memoires of the New York Botanical Garden, 83:95-120.

Hartley, C.W.S. 1988. The Oil Palm. $3^{\text {rd }}$ Ed Longman, London. 761p.

IRHO. 1983. Instructions generales de fecondations artificielles et preparation des graines. Palmier à huile. Institut de Recherches pour les Huiles et les Oléagineux, Paris. 68p.

Meunier, J.; Boutin, D. 1975. L'Elaeis melanococca et l'hybride Elaeis melanococca $x$ Elaeis guineensis. Oléagineux, 30(1):5-8.

Miranda, I.P. de A. 1986. Morfologia e aspectos práticos da germinação e do armazenamento do pólen de pupunha, Bactris gasipaes H.B.K. (Arecaceae). Dissertação de Mestrado, PPG INPA/ FUA, Manaus. 85p.

Miranda, I.P. de A. 1993. Estudos de alguns parâmetros biológicos, químicos $e$ bioquímicos do pólen da pupunheira (Bactris gasipaes Kunth) Arecaceae. Tese de Doutorado, PPG INPA/FUA, Manaus. $152 \mathrm{p}$.
Montgomery, D.C. 1991. Design and analysis of experiments. $3^{\text {rd }}$ ed. John Wiley \& Sons, New York. 649p.

Ooi, S.C.; Silva, E.B. da; Müller, A.A.; Nascimento, J.C. 1981. Oil palm genetic resources: native $E$. oleifera populations in Brazil offer promising sources. Pesquisa agropecuária brasileira, 16(3):385-395.

Praglowski, J.; Punt, W. 1973. An elucidation of the microreticulate structure of the exine. Grana, 13:45-50.

Punt, W.; Wessels Boer, J.G. 1966. A palynological study in cocoid palms. Acta Botanica Neerlandica, 15:255-265.

Roubik, D.W.; Moreno, J.E. 1991. Pollen and spores of Barro Colorado Island. Ed. Missouri Botanical Garden, St. Louis. $268 \mathrm{p}$.

Salgado-Labouriau, M.L. 1973. Contribuição à palinologia dos cerrados. Academia Brasileira de Ciências, Rio de Janeiro. $291 \mathrm{p}$.

Tan, K.S.; Rao, A.N. 1979. Certain aspects of developmental morphology and anatomy of oil palm. Histochemistry, developmental and structural anatomy of Angiosperms: a symposium. pp. 267-285.

Thanikaimoni, G. 1970. Les Palmiers: palynologie et systématique. Tome XI. Institut Français de Pondchéry, Índia. $164 p$. 